\title{
Simulate waste rock flow during co-disposal for dilution control
}

\author{
FRP Basson Newmont Asia Pacific, Australia \\ NJ Dalton Newmont Asia Pacific, Australia \\ BJ Barsanti Newmont Asia Pacific, Australia
}

AL Flemmer Newmont Asia Pacific, Australia

\begin{abstract}
Trucking waste material to surface in deep underground mines is costly, and the benefits of waste co-disposal with cemented paste or hydraulic fill substantial. When co-disposing into primary stopes, a concern is that the waste could accumulate against a secondary stope wall and cause dilution during extraction of adjacent stopes. Waste flow can be controlled with the waste pass design, but dedicated software to simulate the waste flows into the stoping voids is not readily available.
\end{abstract}

Rigid body dynamic physics engines are already used to simulate rockfalls in open pits, and the authors used the three-dimensional fall package Trajec3D to simulate rock flows from waste backfilling into stopes. The aims of the simulations are to gain an understanding of the waste flows, predict waste accumulation areas for different waste pass designs and select an appropriate rate of waste tipping.

Cavity monitoring survey (CMS) triangulation files cannot be directly loaded in Trajec3D, as model preparation must first be done. The paper discusses the preliminary steps to set the model up correctly, the learnings from the authors' simulation attempts, and the rock properties that could be used for simulations.

\section{Introduction}

The Callie underground gold mine (CUG) is located $531 \mathrm{~km}$ north-west of Alice Springs in the Northern Territory. The underground mine has been in production since 1998 with a current mine depth of 1,400 m below surface. The mine haulage system utilises a fleet of 16 trucks which is required to deliver an annual production rate of 2 million ore tonnes to surface, and transport approximately 700,000 waste tonnes to underground rock tips (open stopes). Underground waste repositories are critical to avoid waste haulage to surface, which would negatively impact ore production at CUG by approximately $25 \%$.

In the previous three years, the majority of legacy stope voids have been backfilled with waste rock which has limited the amount of available underground rock tip areas. A key focus at CUG in 2015 is to trial co-disposal of waste material with paste fill into primary stopes to avoid haulage to surface.

When co-disposing into primary stopes, a concern is that the waste could accumulate against a secondary stope wall and cause dilution during extraction of adjacent stopes. Backfill rates for waste disposal must be monitored carefully, but how can this be done effectively to ensure maximum waste disposal without impacting stope wall integrity? Waste flow can be controlled with the waste pass design, but dedicated software to simulate the waste flows into the stoping voids is not readily available. Rill angle calculations based on the waste pass location can be theorised, but this does not account for factors such as coefficient of restitution (COR), or the trajectory of the waste once it enters the stope from the waste pass.

Figure 1 shows a theorised co-disposal diagram of waste rock and paste fill when the waste pass is vertical and located furthest from the stope wall exposure as per Option E in Figure 2. A stand-off distance of D must be maintained to avoid exposing waste rock in the secondary stope. The interaction of paste fill and waste rock during co-disposal is not well understood or documented to the authors' knowledge. 


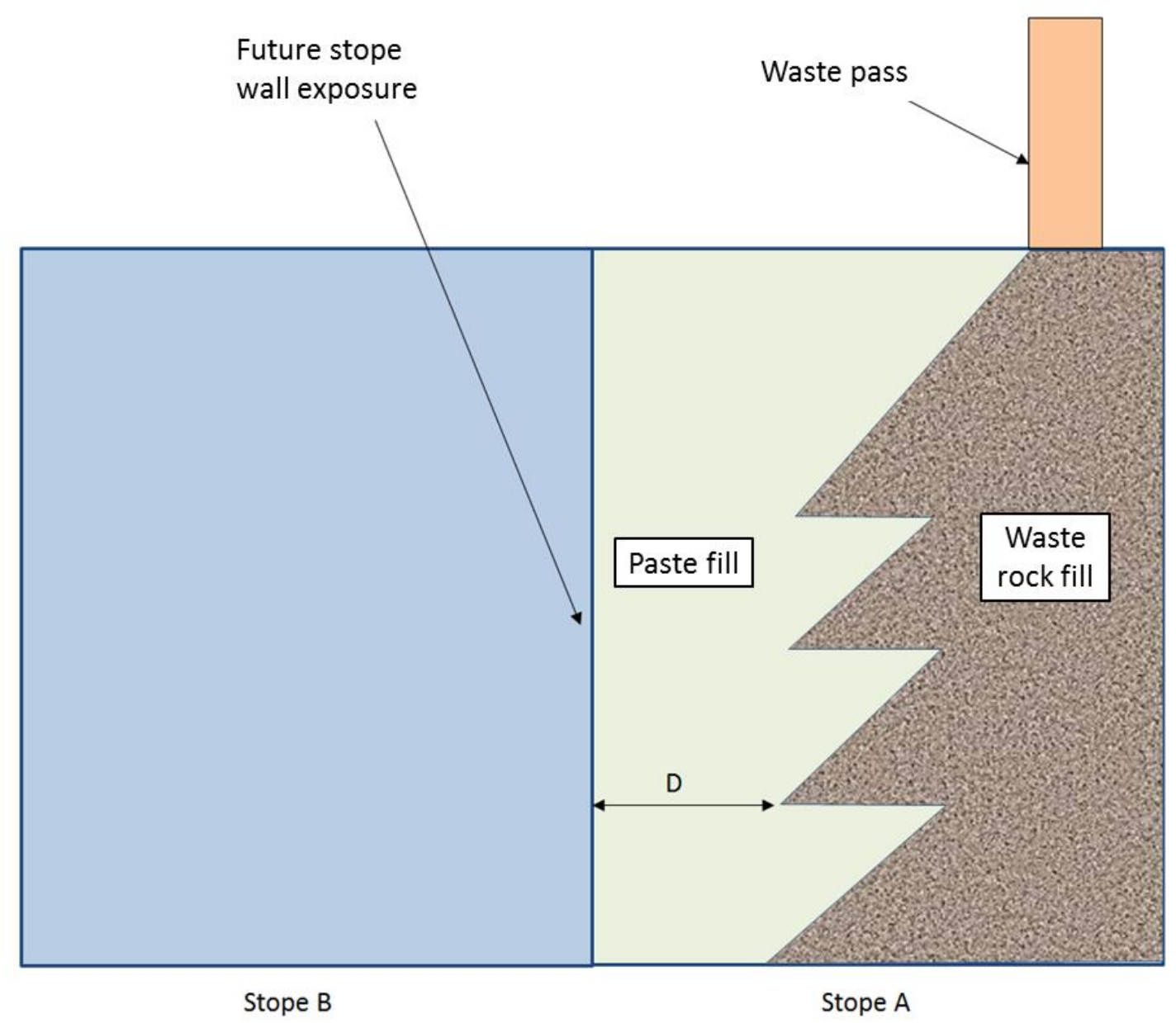

Figure 1 Schematic cross-section of a co-disposal primary stope (Stope A) and an adjacent secondary stope to be extracted after backfilling (Stope B)
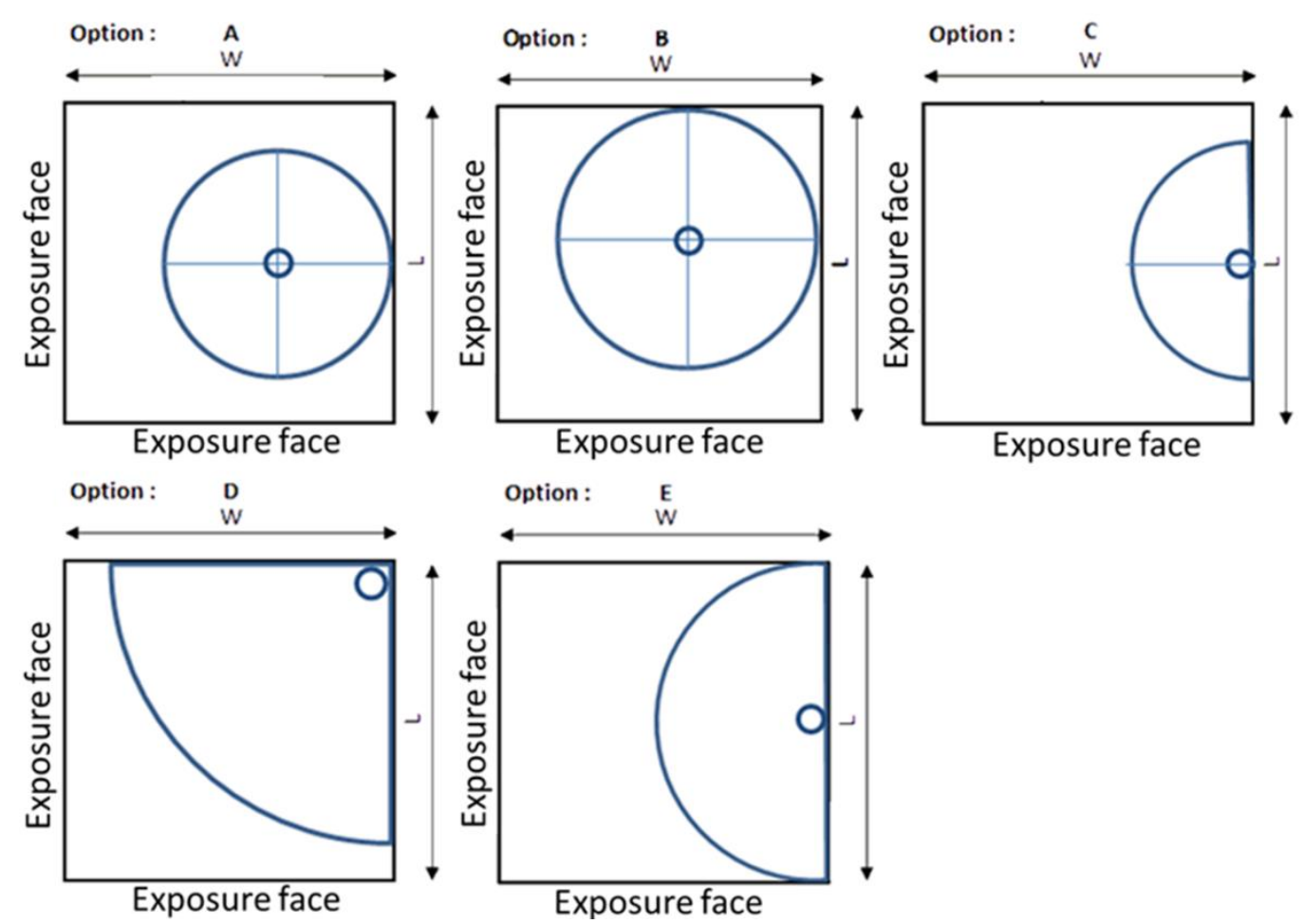

Figure 2 Plan view of various waste rock radial cones depending on stope wall exposure 


\section{Rigid body dynamics physics engines}

A falling rock can experience four types of motion along its path; free fall, rolling, bouncing and sliding as shown in Figure 3. A typical rockfall consists of more than one of these motions during a single event. No interaction takes place between the fall body and slope during free fall, but interactions do take place for all other types of motion during which the rock may also break into smaller pieces. During interaction of the fall body with the slope surface (rolling, bouncing and sliding), the behaviour is largely governed by the geometries and mechanical characteristics of the fall body and slope surface.

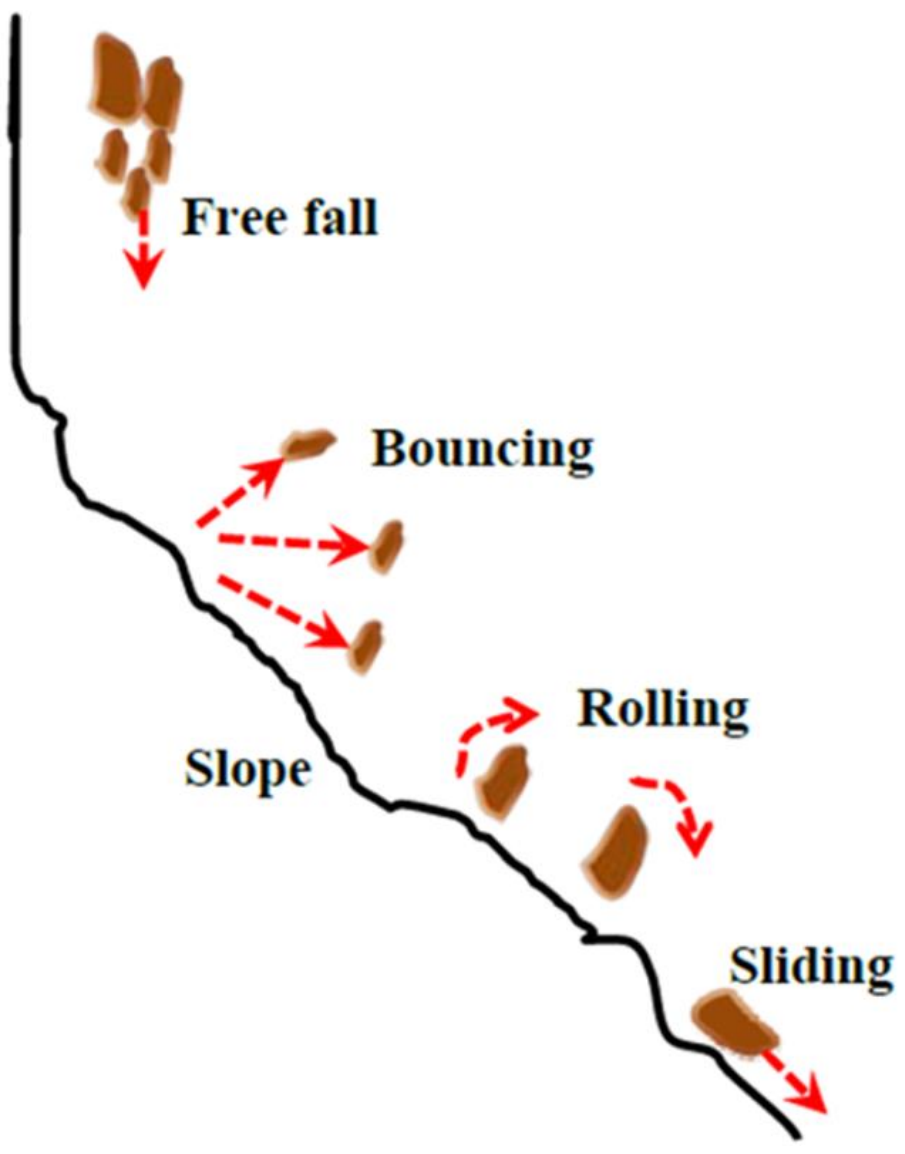

Figure 3 Types of motion during a rockfall (Lo et al. 2008)

Discrete element (DEM) codes can accurately model rock-slope interactions and even simulate break-up, but are time-consuming to set up, require many input parameters that are difficult to estimate, and have slow computational speeds. A less sophisticated approach that still captures the essence of fall body physics is rigid body mechanics. This approach uses the equations of motion and kinematics, assumes an instantaneous period of contact, and a very small contact region between colliding bodies. This method is fast enough for real time simulation of multiple fall bodies and even for probabilistic analysis (Curran \& Hammah 2006).

Trajec3D (BasRock Software for Geotechs 2015) is a three-dimensional rigid body rockfall analysis program that can simulate the trajectory of volumetric shapes during free fall, bouncing, sliding and rolling. It is a modelling tool that enables the quick assessment of scenarios to understand potential fall paths, the time it takes to reach areas of interest, and an estimate of the energy stored along the trajectory. Trajec3D was developed with the Truevision3D graphics library (Truevision3D 2015) and Newton Game Dynamics physics engine (Newton Game Dynamics 2015), which have both been used in commercial applications and games.

The Newton Game Dynamics physics engine implements a deterministic solver that makes it suitable for real-time physics simulations. A comparison by Hummel et al. (2012) between five open source physics engines (Bullet Physics, Newton Game Dynamics, Havok Physics, Open Dynamics Engine and NVIDIA PhysX) 
concluded that the Newton Game Dynamics physics engine is the most accurate, although not always as fast as some of the other physics engines.

"Newton's approach of the deterministic solver appeared to produce indeed most accurate results. Apart from the collision computation performance benchmark, Newton performed always very well." Hummel et al. (2012)

Trajec3D experiments at Boddington Gold Mine confirmed that the Newton Physics Engine reproduces the actual physics behaviour of fall bodies sufficiently accurately for use as a rockfall simulation tool to assess potential outcomes in real life situations (Basson et al. 2013).

\section{Appropriate rock properties for simulations}

The input parameters for rigid body mechanics physics engines are few, measureable and intuitive. In addition to shape, mass and velocity, Trajec3D only requires the elasticity of the contacting surfaces, and static and dynamic friction angles.

Three different types of movement are typical during co-disposal:

- Sliding of the fall bodies down the waste pass, largely governed by the friction angles.

- High speed impacts of fall bodies with stope walls, largely governed by the elasticity of the contacting surfaces (COR).

- Impacts of fall bodies with the paste surface, where their energies are rapidly dissipated. For all practical purposes, the fall bodies are assumed to cease movement at the paste impact location.

\subsection{Coefficient of restitution $\left(C_{R}\right)$}

The elasticity of the contacting surfaces or 'bounciness' is defined by the COR $\left(C_{R}\right)$, a fractional value representing the ratio of speeds after and before impact, taken along the line of impact.

$$
C_{R}=\frac{v}{V}
$$

In Equation 1, $v$ is the scalar velocity of the fall body after impact, and $V$ the scalar velocity of the fall body before impact. When the fall object starts from a zero velocity and bounces from a stationary object, the formula can also be written as Equation 2.

$$
C_{R}=\sqrt{\frac{h}{H}}
$$

In Equation 2, $\mathrm{h}$ is the bounce height of the fall body, and $\mathrm{H}$ the drop height of the fall body.

A COR of one indicates a perfectly elastic collision with no loss in velocity and thus no loss in energy. A value of zero implies a perfectly plastic collision where all the velocity along the line of impact is absorbed. If a fall body impacts a perfectly plastic surface at an angle, the fall body will not come to rest, only the velocity component along the line of impact will be absorbed (Basson 2012).

During site experiments at the Newmont Boddington Gold operations, Graf et al. (2013) reported a typical $C_{R}$-value of 0.12 for hard intact rock surfaces, and 0.003 for soft surfaces of broken rock fragments such as catchment berms.

\subsection{Friction angles}

Although Trajec3D requires a static and dynamic friction angle for contact surfaces, the static angle is seldom used during simulations. The static friction angle is only used when fall body interactions are 
activated in the software and a moving fall body interacts with a stationary fall body, but the dynamic friction angle is used during all sliding movements.

During co-disposal, the selected friction angle will have most impact on the body velocity during sliding down the waste pass. This will determine the waste pass exit velocity of the fall body when entering the stope void, and the energy available during collisions with the stope walls.

The friction angle is a difficult value to estimate, as the value is a function of the sliding surface and fall body shape. Figure 4 shows the movement of discs or flat cylinders (yellow), square boxes (green) and angular flattened spheres (blue) with different friction angles down a plane. All the objects slide down the slope when their friction angles are less than the slope gradient. When the friction angles exceed the slope gradient, the flat shapes stop shortly after release, but the volumetric shapes start to tumble down the slope (Basson 2012).

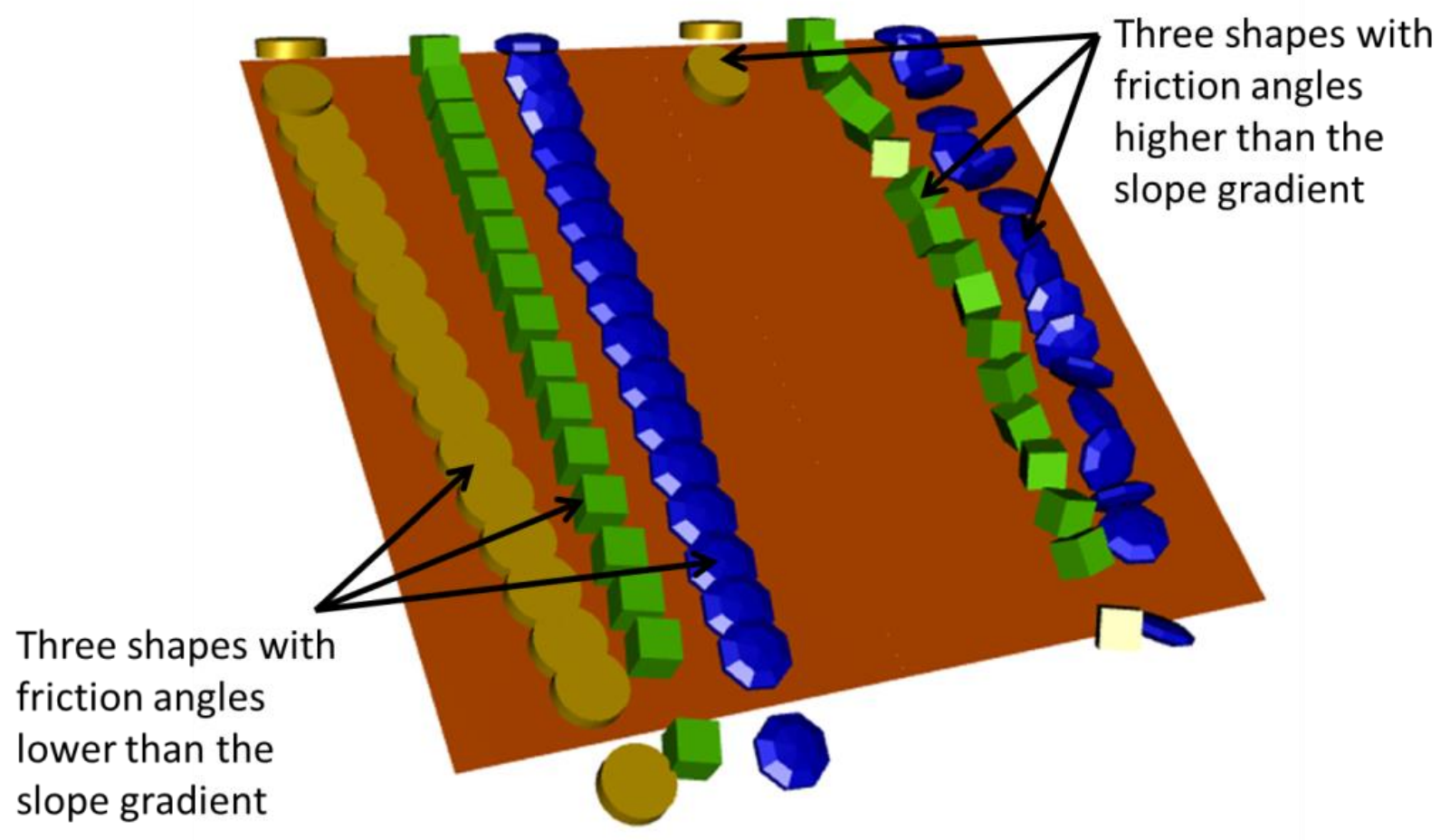

Figure 4 Friction angle impact on motion

The selected friction angle value should take account of the waste pass development method, as a raisebored pass will have a value close to the laboratory friction angle, and a blasted pass will have a substantially higher value.

\section{$4 \quad$ Stope triangulation preparation for Trajec3D}

Simulating rockfalls in open pits and underground voids are conceptually similar, but visually different. Open pit engineers are used to inspecting a pit shell surface, which is also the physics interaction surface with the fall bodies. Underground engineers are used to looking at the outside shell of stope voids, but the physics interaction surface is at the inside of the stope void mesh. Figure 5 shows the difference in appearance of a stope mesh with the polygon normals pointing away from the void on the left, and the polygon normals pointing inwards (towards the void) on the right. 

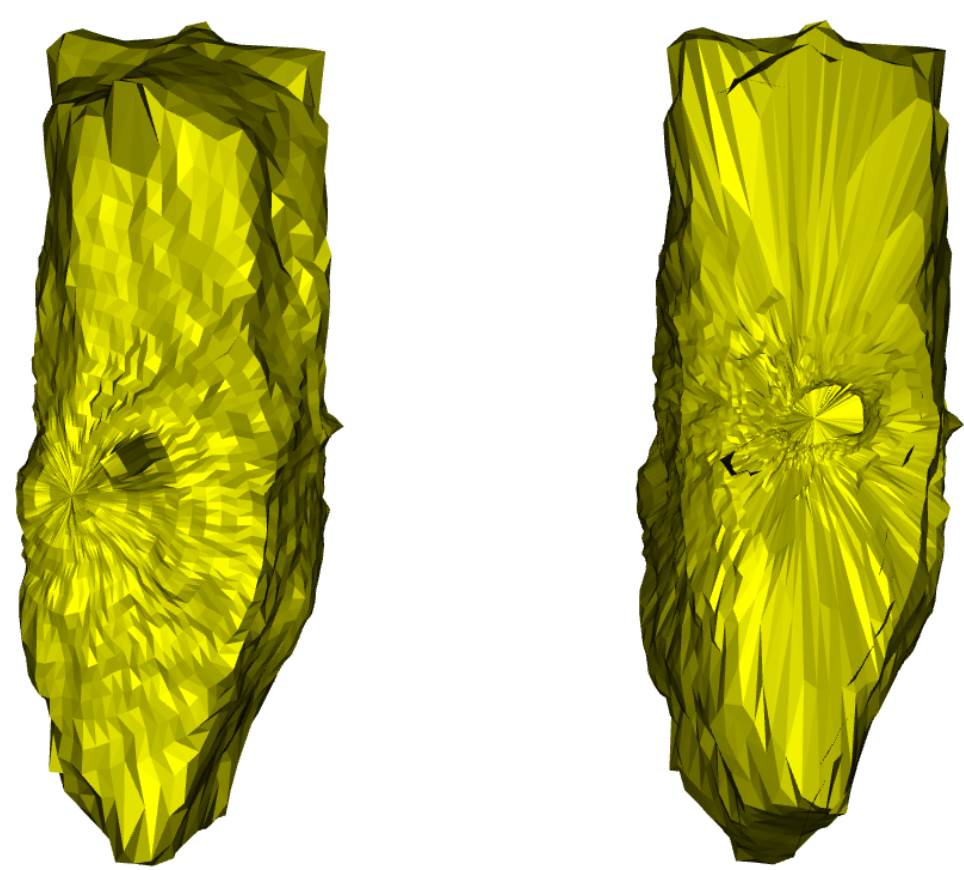

Figure 5 Visual differences of a mesh with different polygon normal convention

Polygons are the individual surfaces of a mesh, and only one sided. A polygon is thus visible from only one side and invisible from the other. As this causes difficulties for users, visualisation software packages normally create back-to-back mirror surfaces and polygons thus appear double sided. Although this is unimportant when visualising the mesh, it is important when loading a mesh into a physics engine. In a physics engine, only the visible side of a polygon will be assigned with the physics interaction properties.

Before a mesh can be loaded into Trajec3D, the graphics engine of the mine design software has to be set to display the polygons without their flipped mirror polygons. This is normally done by activating 'backface culling' in the software settings. If the polygons are not visible on the mesh inside the void, then the polygon normals need to be flipped prior to loading the mesh into Trajec3D.

\section{$5 \quad$ Waste rock simulations}

The purpose of the simulations for this paper is to verify if Trajec3D can simulate realistic waste rock behaviour during backfilling, test the sensitivity of input parameters, and explore visualisation options for analysing and presenting the trajectory data. A total number of 100 simulations were run to test the sensitivity of a variety of input parameters, and each simulation contained 100 fall bodies.

\subsection{Input parameters}

The simulation inputs can be divided into spatial and interaction variables. The spatial or geometry variables include factors such as the mass and shape of the waste rock; size, length and geometry of the stope; and length, dip, width and location of the waste pass. The interaction variables are the COR and the friction angles. The range of input parameters that were tested are summarised in Table 1, with only selected aspects discussed in more detail. 
Table 1 Simulation input parameters

\begin{tabular}{|c|c|c|}
\hline Simulation variable & Value/range used & Comment \\
\hline $\begin{array}{l}\text { Mass of the waste } \\
\text { rock }\end{array}$ & 0.5 and $3.0 \mathrm{t}$ & $\begin{array}{l}\text { A good estimate of the largest development waste size } \\
\text { at CUG is } 0.5 \mathrm{t} \text {. Large } 3.0 \mathrm{t} \text { fall bodies were also } \\
\text { simulated to determine the impact of fall body size. }\end{array}$ \\
\hline $\begin{array}{l}\text { Shape of the waste } \\
\text { rock }\end{array}$ & $\begin{array}{l}\text { Angular flat cylinder } \\
\text { Angular rough sphere } \\
\text { Flat elongated box }\end{array}$ & $\begin{array}{l}\text { Actual shape will be a function of the ground conditions } \\
\text { and blasting practices. }\end{array}$ \\
\hline $\begin{array}{l}\text { Stope size, length and } \\
\text { geometry }\end{array}$ & Actual stope CMS & $\begin{array}{l}\text { Determine the free fall distance and allowed scatter. } \\
\text { The chosen stope guaranteed at least one wall } \\
\text { interaction for all simulations. }\end{array}$ \\
\hline $\begin{array}{l}\text { Length of the waste } \\
\text { pass }\end{array}$ & 15 and $35 \mathrm{~m}$ & $\begin{array}{l}\text { Determine exit velocity into the stope and a function } \\
\text { of the level spacing, which determines the ore pass } \\
\text { length. }\end{array}$ \\
\hline Dip of the waste pass & 65 and $85^{\circ}$ & $\begin{array}{l}\text { Controls the exit velocity, and in combination with the } \\
\text { friction angle, if sliding or tumbling will occur. }\end{array}$ \\
\hline $\begin{array}{l}\text { Location of the waste } \\
\text { pass }\end{array}$ & 2 locations & $\begin{array}{l}\text { An important factor in the distribution of the waste, } \\
\text { but options are limited to available development. }\end{array}$ \\
\hline COR & 0.1 and 0.2 & $\begin{array}{l}\text { Newmont Boddington Gold reported an average value } \\
\text { of } 0.12 \text { for their hard rock collisions (Graf et al. 2013). }\end{array}$ \\
\hline $\begin{array}{l}\text { Dynamic friction } \\
\text { angle }\end{array}$ & 30 and $50^{\circ}$ & $\begin{array}{l}\text { Could potentially affect the type of movement (sliding } \\
\text { or tumbling) and exit speed from the waste pass. }\end{array}$ \\
\hline
\end{tabular}

\subsection{Simulation results}

As expected, the location and dip of the waste pass are the primary controls on waste distribution. The location of the pass determines the entry point of the waste rock into the stope, and the angle controls the velocity of the fall bodies. The secondary controls on the distribution are the length of the waste pass, and the friction angle between the fall bodies and pass surface. Figure 6 shows the fall body trajectories for the same set of input parameters and different waste pass angles (Figure 6(a)), and pass lengths (Figure 6(b)). 


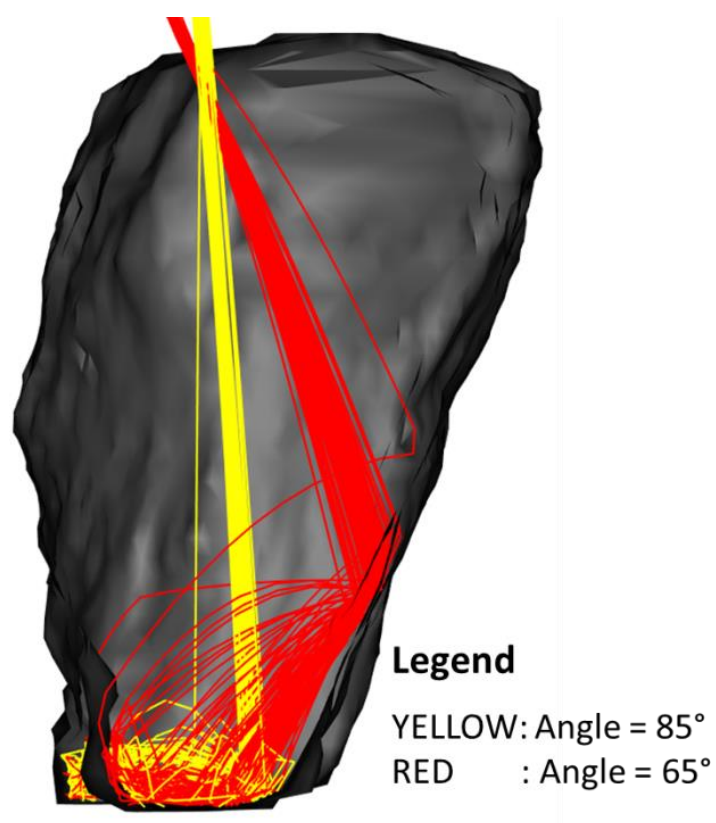

(a)

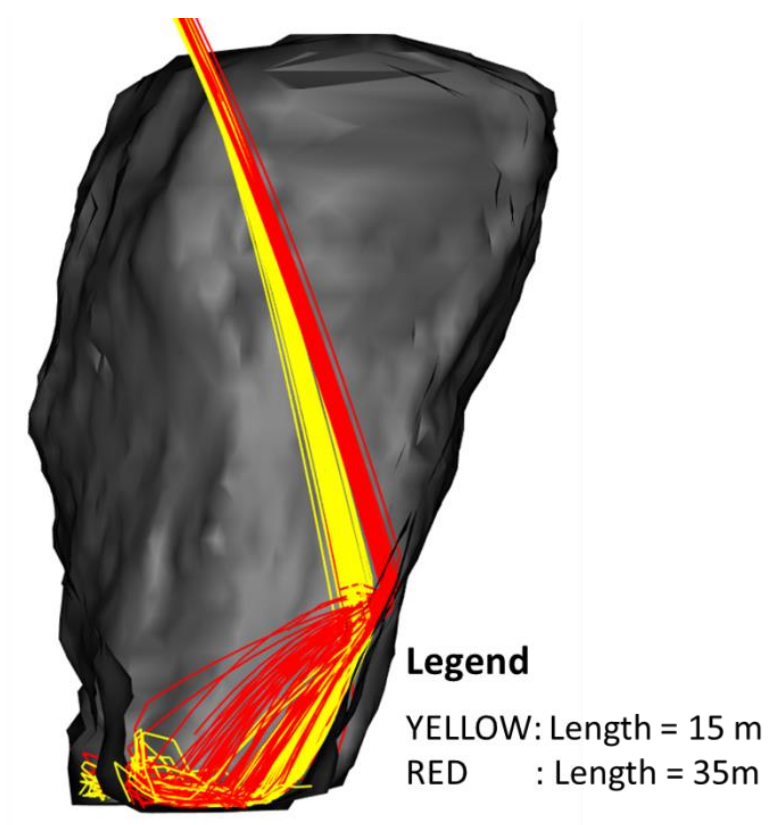

(b)

Figure 6 Changes in fall body trajectories by varying the waste pass angle (a) from 85 to $65^{\circ}$, and the pass length (b) from 15 to $35 \mathrm{~m}$

Longer waste passes result in higher exit velocities, which cause larger scatter in the waste material trajectories. The increased pass length allows for a larger variation in the exit velocities, especially when tumbling occurs as shown in Figure 7. The exit velocities for the same pass lengths are in a similar range irrespective of whether sliding or tumbling occurred in the pass, but tumbling does result in an increased spread of the trajectories.

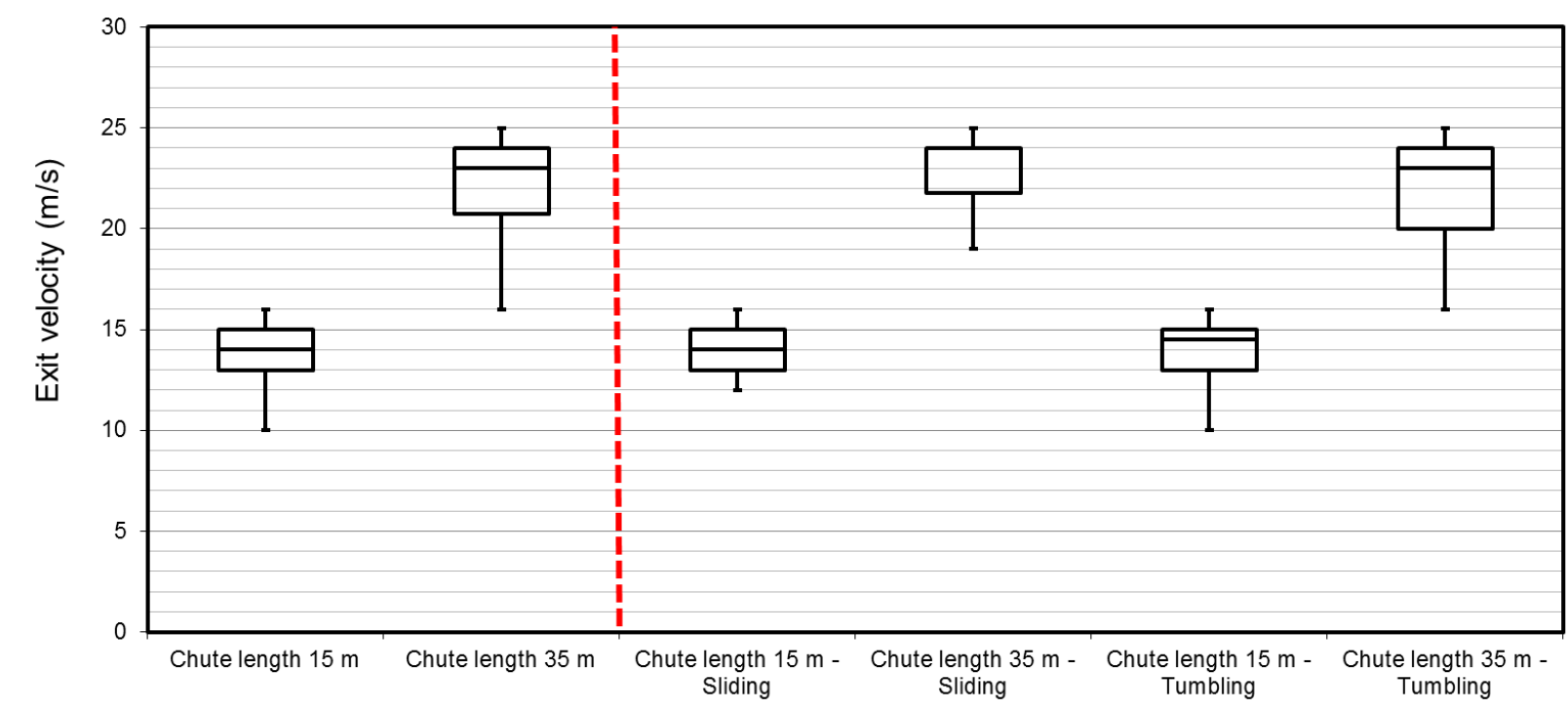

Figure 7 Fall body exit velocities with different waste pass (chute) lengths

An unexpected outcome from the simulations was that no discernible relation could be found between the fall body shape and waste pass exit velocity as shown in Figure 8. 


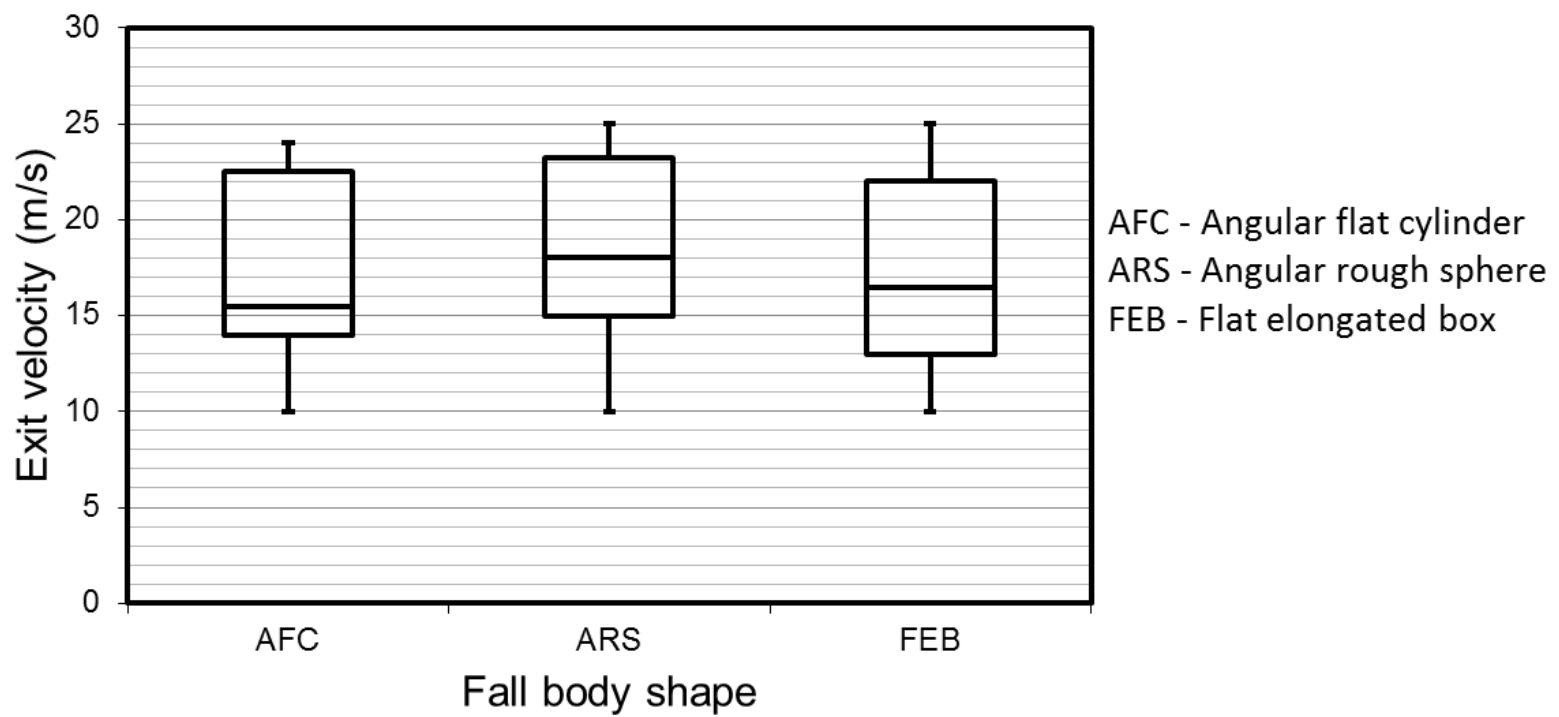

Figure 8 Distribution of exit velocities for different fall body shapes

The most important test area for the effect of the COR on trajectories was the interaction of fall bodies with a stope wall before landing on paste. Figure 9 shows an example of a typical trajectory change from different coefficients of restitution (COR).

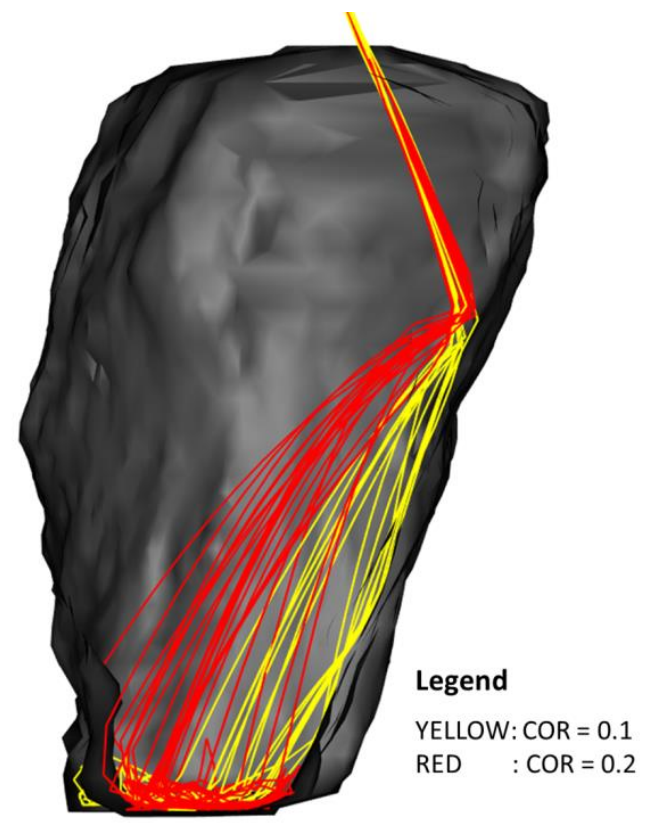

Figure 9 Fall body trajectories for different COR values

Changing the size of the fall bodies has minimal impact on the results. Due to the different centre of gravity for different fall body sizes, the initial paths appear slightly off-set, but their trajectories after a wall collision are nearly identical.

\section{Trajectory density visualisation}

Although the trajectory strings are useful in most cases, it does not quantify the amount of anticipated rock at a particular location. A density visualisation method was developed to give the trajectory information quantifiable meaning at the level where the waste rock impacts the paste surface. An assumption for this 
method is that the paste will absorb all fall body movement, and the fall body will be arrested at the impact location.

A density iso-surface function is available in GEM4D (BasRock Software for Geotechs 2015) and was used to produce the Figure 10 images. The method creates a regular block of grid points (similar to a block model) around the trajectory points, and the number of trajectory impacts is calculated for each cell. These trajectory density values are then iso-surfaced as in Figure 10(a), or multiple iso-surfaces sliced to produce the horizontal line contours in Figure 10(b). These values have quantifiable meaning; for example, every square meter within the blue horizontal contour lines will contain at least $0.5 \%$ of the initially dumped material, increasing to $2.5 \%$ for the red contour lines.

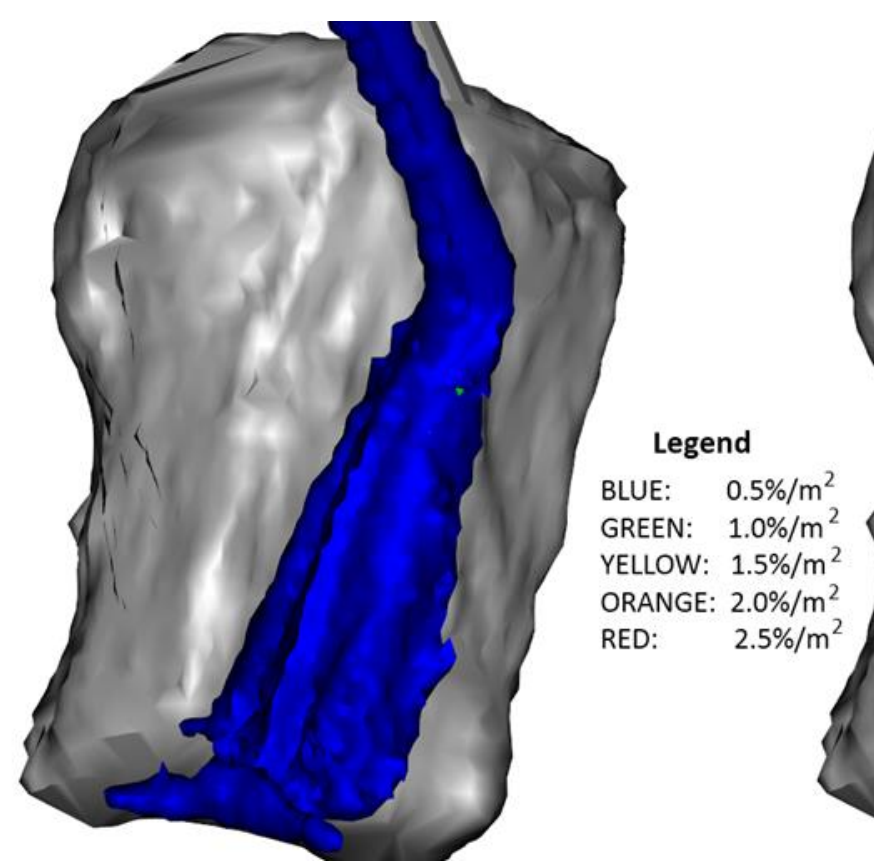

(a)

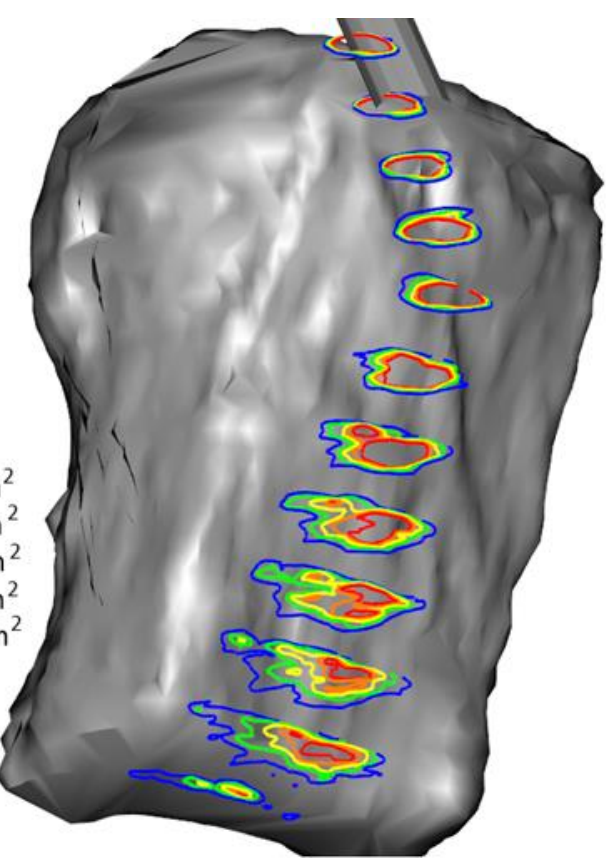

(b)

Figure 10 Perspective view of the trajectory densities as an iso-surface (a) and contours on different levels (b)

The eventual aim is to develop a relationship between the iso-surface values and the amount of material that can be safely co-disposed into a stope, without resulting in dilution loss when extracting adjacent stopes.

\section{Conclusion}

Trajec3D is able to simulate waste rock flows and seems to capture the main aspects that would influence trajectory spreads and thus the accumulation areas for the waste rock. The rigid body dynamics physics engine is able to simulate all four modes of motion a falling rock can experience namely free-fall, rolling, bouncing and sliding.

From the simulations, the primary controls for trajectory spread is waste pass location and dip, and secondary controls the length of the waste pass, COR, and friction angle between the fall body and waste pass surface. Rock size seems to have a negligible impact on the results.

Further work is required to establish a relationship between density iso-surface values, the distance from the wall that will be exposed, and the amount and the rate at which waste material than can be disposed. 


\section{Acknowledgement}

The authors gratefully acknowledge the permission given by Newmont Asia Pacific, and Newmont Tanami Operations in particular, to publish this paper.

\section{References}

BasRock Software for Geotechs 2015, viewed 10 July 2015, http://www.basrock.net

Basson, FRP 2012, 'Rigid body dynamics for rock fall trajectory simulation', Proceedings of the 46th US Rock Mechanics/Geomechanics Symposium, American Rock Mechanics Association, Minneapolis, MN, 7 p.

Basson, FRP, Humphreys, R \& Temmu, A 2013, 'Coefficient of restitution for rigid body dynamics modelling from onsite experimental data', in P Dight (ed.), Proceedings of the 2013 International Symposium on Slope Stability in Open Pit Mining and Civil Engineering (Slope Stability 2013), Australian Centre for Geomechanics, Perth, pp. 1161-1171.

Curran, JH \& Hammah, RE 2006, 'Seven lessons of geomechanics software development', in DP Yale (ed.), Proceedings of the 41st US Symposium on Rock Mechanics (USRMS), American Rock Mechanics Association, Minneapolis, MN, $15 \mathrm{p}$.

Graf, C, Peryoga, T, McCartney, G \& Rees, T 2013, 'Verification of Trajec3D for use in rockfall analysis at Newmont Boddington Gold', in P Dight (ed.), Proceedings of the 2013 International Symposium on Slope Stability in Open Pit Mining and Civil Engineering (Slope Stability 2013), Australian Centre for Geomechanics, Perth, pp. 1231-1242.

Hummel, J, Wolff, R, Stein, T, Gerndt, A \& Kuhlen, T 2012, 'An evaluation of open source physics engines for use in virtual reality assembly simulations', in G Bebis, R Boyle, B Parvin, D Koracin, F Charless, W Sen, C Min-Hyung, S Mantler, J Schulze, D Acevedo, K Mueller \& M Papka (eds), Proceedings of the 8th International Symposium on Visual Computing (ISVC 2013), Advances in visual computing, Part II (LNCS 7432), Springer-Verlag, Berlin, pp. 346-357.

Lo, CM, Lin, ML \& Lee, WC 2008, 'Talus deposition pattern of rockfall through mechanical model and remote sensing technology', Geophysical Research Abstracts, vol. 10.

Newton Game Dynamics 2015, viewed 10 July 2015, http://newtondynamics.com

TrueVision3D 2015, viewed 10 July 2015, http://www.truevision3d.com 
